\title{
Neurologic Involvement in Scleroderma en Coup de Sabre
}

\author{
Tiago Nardi Amaral, ${ }^{1}$ João Francisco Marques Neto, ${ }^{1}$ Aline Tamires Lapa, ${ }^{2}$ \\ Fernando Augusto Peres, ${ }^{3}$ Caio Rodrigues Guirau, ${ }^{3}$ and Simone Appenzeller ${ }^{1,3}$ \\ ${ }^{1}$ Rheumatology Division, Faculty of Medical Science, State University of Campinas, 13083-970 Campinas, SP, Brazil \\ ${ }^{2}$ Postgraduate Program in Child and Adolescent Health, Faculty of Medical Science, State University of Campinas, \\ 13083-970 Campinas (UNICAMP), Brazil \\ ${ }^{3}$ Rheumatology Lab, Faculty of Medical Science, State University of Campinas, 13083-970 Campinas, SP, Brazil
}

Correspondence should be addressed to Simone Appenzeller, appenzellersimone@yahoo.com

Received 31 October 2011; Accepted 4 December 2011

Academic Editor: Jozélio Freire de Carvalho

Copyright () 2012 Tiago Nardi Amaral et al. This is an open access article distributed under the Creative Commons Attribution License, which permits unrestricted use, distribution, and reproduction in any medium, provided the original work is properly cited.

Localized scleroderma is a rare disease, characterized by sclerotic lesions. A variety of presentations have been described, with different clinical characteristics and specific prognosis. In scleroderma en coup de sabre (LScs) the atrophic lesion in frontoparietal area is the disease hallmark. Skin and subcutaneous are the mainly affected tissues, but case reports of muscle, cartilage, and bone involvement are frequent. These cases pose a difficult differential diagnosis with Parry-Romberg syndrome. Once considered an exclusive cutaneous disorder, the neurologic involvement present in LScs has been described in several case reports. Seizures are most frequently observed, but focal neurologic deficits, movement disorders, trigeminal neuralgia, and mimics of hemiplegic migraines have been reported. Computed tomography and magnetic resonance imaging have aided the characterization of central nervous system lesions, and cerebral angiograms have pointed to vasculitis as a part of disease pathogenesis. In this paper we describe the clinical and radiologic aspects of neurologic involvement in LScs.

\section{Introduction}

Scleroderma is a rare disease of unknown etiology, characterized by thickening and hardening of skin resulting from increased collagen production. The term includes a variety of diseases, from localized scleroderma (LS) to systemic sclerosis. LS is traditionally considered to be limited to skin, subcutaneous tissue, underlying bone, and, in craniofacial subtype, nervous system involvement [1]. Recent studies, however, have described malaise, fatigue, arthralgia, and myalgia in morphea. Moreover, rheumatologic, ophthalmologic and neurologic symptoms and signs have been described in up to $20 \%$ of the patients with LS. Based on these findings LS ought to be differentiated from systemic sclerosis by the absence of sclerodactylya, Raynaud's phenomenon, and capillaroscopic abnormalities [1].

LS incidence ranges from 0.4 to 2.7 per 100,000 people [2]. Although present in all races, the prevalence among Caucasians is increased, summing up 72 to $82 \%$ of the patients [2]. Females are primarily affected [1], and a similar distribution between children and adults occurs $[1,3]$.
Disease incidence peaks in the fifth decade of life in adults, whereas $90 \%$ of children are diagnosed between 2 and 14 years of age $[1,3-5]$.

Linear scleroderma en coup de sabre (LCsc) is a rare subset of LS. The typical presentation affects frontoparietal region, and the mean age of onset is around 13 years old [1]. In this paper, clinical presentation of LScs and its neurological involvement are described.

\section{Pathogenesis}

Skin pathogenesis seems to be similar between LScs, LS, and systemic sclerosis, although not fully understood $[1,6-8]$. Clinical and pathological data support the hypothesis that vasculature is the primary target in LS $[6,7,9]$. Early skin biopsies revealed damaged endothelial cells preceding the development of fibrosis by months to years. Increased vascular permeability is associated with mononuclear cell infiltration, leading to perivascular inflammatory cell infiltrates, vascular intimal thickening, and vessel narrowing [8]. Gradually, the vessels lose their elasticity; media and 
TABLE 1: Localized scleroderma classification.

\begin{tabular}{|c|c|c|c|c|}
\hline Classification & Subtypes & Characteristic lesions & Tissues involved & Main Site \\
\hline \multirow[b]{2}{*}{ Circumscribed morphea } & Superficial variant & Oval lesions & Limited to epidermis and dermis & Trunk \\
\hline & Deep variant & Oval lesions & $\begin{array}{l}\text { Deep indurations. Dermis and } \\
\text { subcutaneous tissue involved. } \\
\text { Variable muscle and fascia } \\
\text { involvement }\end{array}$ & Trunk \\
\hline \multirow{3}{*}{$\begin{array}{l}\text { Linear morphea } \\
\text { (linear scleroderma) }\end{array}$} & Trunk/limb variant & Linear indurations & $\begin{array}{l}\text { Dermis and subcutaneous tissue } \\
\text { (may involve muscle and bone) }\end{array}$ & Trunk/limb \\
\hline & $\begin{array}{l}\text { Head variant } \\
\text { (en coup de sabre) }\end{array}$ & Linear indurations & $\begin{array}{l}\text { Dermis of the frontoparietal area } \\
\text { (may involve muscle, bone, and } \\
\text { central nervous system) }\end{array}$ & Face and scalp \\
\hline & $\begin{array}{l}\text { Parry-Romberg } \\
\text { syndrome }\end{array}$ & & $\begin{array}{l}\text { Dermis, subcutaneous tissue, } \\
\text { muscle, cartilage, and bone }\end{array}$ & Unilateral face \\
\hline Generalized morphea & & $\begin{array}{c}\text { Four or more indurated } \\
\text { plaques }>3 \mathrm{~cm} \text { each }\end{array}$ & $\begin{array}{l}\text { Usually limited to the dermis and } \\
\text { rarely involves subcutaneous tissue }\end{array}$ & $\begin{array}{c}\text { Diffuse } \\
\text { (no face and hand) }\end{array}$ \\
\hline Pansclerotic morphea & & $\begin{array}{c}\text { Circumferential } \\
\text { involvement }\end{array}$ & $\begin{array}{l}\text { Epidermis, dermis, subcutaneous } \\
\text { tissue, muscle and bone }\end{array}$ & Limbs \\
\hline Mixed variant morphea & & & $\begin{array}{l}\text { Combination of } 2 \text { or more previous } \\
\text { subtypes }\end{array}$ & \\
\hline
\end{tabular}

adventitia become fibrotic and more prone to small-artery occlusion. The latter is further exacerbated by thrombotic events driven by platelets activation, resulting in fibrosis and end-organ damage [8].

The inciting event for microvascular damage remains unknown. Preceding trauma has been observed as initial event in pediatric population $[10,11]$. Previous infection, particularly due to Borrelia burgdorferi, has been implicated in Europe and Japan, but not confirmed in the United States $[12,13]$. Genetics participation in pathogenesis appears to be relatively weak, since only a $4.7 \%$ concordance between twins has been observed [14] and family studies revealed only $1.6 \%$ frequency among first-degree relatives [8, 15]. However, several groups have identified polymorphisms in potential candidate genes involved in immune regulation, such as BANK1, C8orfl3-BLK, IL-23R, IRF5, STAT4, TBX21, and TNFSF4, which may underlie the pathogenesis of systemic sclerosis $[8,16]$. Intriguingly, many of these polymorphisms are shared with other rheumatic diseases, such as systemic lupus erythematosus.

More than 1800 genes are differentially expressed in scleroderma skin compared to healthy controls; however analysis of visually unaffected skin reveals a similar gene expression as diseased skin $[17,18]$. Altered gene expression is mapped to fibroblasts, endothelial, epithelial, smooth muscle, T, and B cells [8]. Recently, Gardner et al. have found significant gene-expression signature in systemic sclerosis patients, which has been mapped to TGF- $\beta$ and WNT signaling pathways, the production of extracellular matrix proteins and CCN family proteins [18].

Pathogenesis of CNS involvement in LScs is due to perivascular infiltrate and vasculitis $[9,19,20]$; however biopsy is not routinely done and histological findings are available only for patients with severe neurological findings. Gliosis, suggesting chronic inflammatory process, leptomeningeal band-like sclerosis, and thickened blood vessels' walls, as well as intraparenchymal calcification, have also been described in the few available studies $[9,19,20]$.

To sum up, available data suggests a complex pathogenesis of scleroderma, in which blood vessels, the immune system, and extracellular matrix are affected and may contribute to the development of the disease.

\section{Clinical Presentation}

Ivory-colored, sclerotic lesions, with violaceous borders, characterize LS. Number and distribution of lesions vary, as well as their extent. These characteristics and tissue involvement (dermis, subcutaneous tissue, fascia, and muscle) determine the localized scleroderma classification (Table 1) [1, 21].

LScs presents in a band-like fashion on the frontoparietal scalp and forehead. Alopecia is common and many times is the patient's main concern. Skin lesions may extend to the nose, cheek, chin, and neck $[8,22,23]$ and usually have an active stage lasting 2-5 years $[24,25]$. Muscle, cartilage, and bone lesions incur in facial atrophy: in this scenario, ParryRomberg syndrome (PRS) must be considered a differential diagnosis. Up to $28 \%$ of patients having LScs manifests PRS features, such as a unilateral slowly progressive atrophy of the face. PRS commonly affects dermatomes of trigeminal nerve. Skin, soft tissue muscles, and underlying bone structures are involved [26]. Skin hyperpigmentation and discoloration and hairless patches can be present. Many authors postulate that LScs and PRS are clinical variants of the same disease. Arguments for PRS inclusion on the spectrum of LS disorders are compelling. LScs and PRS coexist in 20-37\% of the patients with LScs diagnosis, and both conditions have similar age of onset and disease course [27]. Furthermore, dermatologic findings in PRS are sometimes indistinguishable from those of LS [27]. However, some authors still consider them as different entities, since PRS does not always 
TABle 2: Clinical aspects of linear scleroderma en coup de sabre (LScs) and Parry-Romberg syndrome (PRS).

\begin{tabular}{lll}
\hline Skin & LScs & PRS \\
\hline Initial site & $\begin{array}{l}\text { Induration and } \\
\text { thickening }\end{array}$ & Not affected \\
\hline Fpreading pattern & Forehead and scalp & Cheek and nose \\
\hline $\begin{array}{l}\text { Usually does not } \\
\text { spread below the } \\
\text { forehead } \\
\text { Occasionally affects } \\
\text { nose, cheek, chin, and } \\
\text { neck }\end{array}$ & $\begin{array}{l}\text { Usually affects } \\
\text { lower face } \\
\text { Occasionally bilateral } \\
\text { rested to one } \\
\text { side }\end{array}$ \\
\hline Systemic involvement & Yes & No \\
\hline Intracranial involvement & Yes & Yes \\
\hline
\end{tabular}

have skin thickening [28-30] and the hemifacial atrophy occurring in PRS is usually more prominent [25] (Table 2).

The diagnosis is clinical and based on characteristic cutaneous and soft tissue findings $[6,24,25]$. Currently no diagnostic laboratory tests exist. Nonetheless, $37-50 \%$ of the patients may present a positive ANA test (homogenous or speckled patterns) $[2,6,24]$, as well as anti-single-stranded-DNA antibodies $[5,31,32]$. Antinucleosome antibodies, soluble interleukine- 2 receptor, and, recently, antiagalactosyl immunoglobulin G antibodies have been reported in LS [33-35]. In some patients, autoantibody may be present even before the disease manifestation and patients with Scl-70, anticentromere, Ro/La, or U1RNP antibodies should be followed closely, as systemic disease might ensue [6].

\section{Neurologic Involvement}

LScs has been associated with a variety of neurologic abnormalities and typically is preceded by the development of cutaneous disease by months to years $[8,31,36,37]$. Nervous system involvement is usually not correlated to skin activity and may present years after the disease initial symptomatology [37]. In 16\% of cases, neurologic symptoms predate the cutaneous manifestations [27].

Neurological symptoms and signs in LScs are protean and include epilepsy $[8,38,39]$, headache $[27,40]$, focal neurologic deficits, and movement disorders [27, 31, 36, 41, 42 ], as well as neuropsychiatric symptom and intellectual deterioration [43-45].

4.1. Epilepsy. Epilepsy is a frequently reported manifestation in LScs. An analysis of 54 patients with LScs or PRS has revealed a prevalence of $73 \%$ of seizures, $33 \%$ of them refractory to antiepileptic medications [27]. Complex partial seizures have been reported most frequently, followed by tonic-clonic, absence seizures, as well as status epilepticus $[9,38,39]$. Electroencephalography analyses show abnormalities in the majority of patients. Some authors advocate that brain lesions of LS are more epileptogenic than those of other autoimmune disorders [27].
4.2. Focal Neurologic Deficits and Movement Disorders. Focal neurologic deficits and movement disorders secondary to brain lesions have also been described, but seem to be relatively uncommon $[27,36,41]$. In an analysis of 54 patients, focal neurological deficits were described in $11 \%$ of patients at presentation and in 35\% of patients overall [27]. While facial palsy and extraocular movement disorder may be due to cutaneous involvement, trigeminal neuralgia [31] and masticatory spasms [42] are considered primary neurologic involvement.

4.3. Other Neurological Findings. Around 35\% of LScs patients refer headache, which is usually associated with other neurologic complaints [27]. Few studies have investigated headache subtype, but migraines and mimics of hemiplegic migraine seem to be more prevalent $[27,40]$.

Neuropsychiatric symptoms have been described in 15\% of patients, including behavioral changes and progressive intellectual deterioration with [43-45] or without seizures [46].

\section{Neuroimaging}

Computed tomography (CT) and magnetic resonance (MRI) studies have shown central nervous system abnormalities in LScs patients. Neurologic findings are more frequently ispilateral to the skin lesions, but contralateral involvement has been described $[19,36]$. Neurologic symptoms should not be used as a predictor for MRI abnormalities because neurologic lesions have been discovered in asymptomatic patients [30, 47]. Moreover, symptomatic patients were sometimes proven to have normal radiologic exams.

Outer diploe thinning, cerebral atrophy, white matter lesions, focal subcortical calcifications, and meningocortical alterations have been described $[30,35]$. Intraparenchymal calcifications involving basal ganglia, thalami, and dentate nuclei are the most common brain lesion in LScs patients [30, 47, 48]. Characteristically, the calcifications are ipsilateral $[46,49]$, but contralateral involvement may occur $[36,50]$.

MRI usually exhibits T2 hyperintensities, mostly in subcortical white matter, but also in corpus callosum, deep grey nuclei, and brain stem $[29,30,40,46,47,51,52]$.

Cerebral atrophy is generally subtle, characterized by blurring of the gray-white interface, cortical thickening, and abnormal gyral pattern [30]. Atrophy is usually focal but widespread lesions involving an entire cerebral hemisphere have been described $[30,46,52]$. Hippocampal atrophy is unusual, but has been reported [28, 35]. Infratentorial lesions and cerebellar hemiatrophy have been observed in patients presenting more severe neurological symptoms [27].

Cerebral angiograms and magnetic resonance angiograms studies showed vascular involvement suggestive of vasculitis. Reports of cerebral aneurysms and other vascular malformations, as brain cavernomas $[48,53,54]$, exist and could represent late sequelae of vasculitic process.

\section{Treatment}

At this moment, no randomized controlled trials exist for LScs. In a retrospective study of LScs and/or PRS patients 
conducted at a tertiary care center, antimalarials, methotrexate, topical and oral steroids, and tetracycline were used for cutaneous disease, but no definite conclusions could be drawn due to the small sample size and the absence of a control group [55]. D-penicillamine, methylprednisolone, mycophenolate mofetil, and methotrexate might be considered in the treatment of neurologic involvement of LScs [9]. In reported cases, association of methotrexate or mycophenolate mofetil and steroids appeared to have impact in controlling intractable seizures and stabilizing central nervous system damage $[27,40,44,48,56]$.

\section{Conclusion}

Once believed to exclusively involve skin, subcutaneous tissue, and bone, LS has been associated to systemic symptoms. Rheumatologic, ophthalmologic, and neurologic manifestations seem to be present in around $20 \%$ of the patients, and, in those with LScs, nervous system disorders are the most prevalent extracutaneous presentation.

Neurologic damage in LScs is frequent and independent of clinical signs and symptoms. Radiologic findings and pathologic studies point towards a neurovasculitic hypothesis. The investigations of choice are CT, to detect skull abnormalities, and MRI, to identify underlying brain lesions. Neuroimaging studies should be considered in all LScs patients at the time of the diagnosis. Longitudinal studies should be done to identify progression, even in asymptomatic patients.

\section{Acknowledgment}

Dr. S. Appenzeller was granted by Fundação Apoio À Pesquisa Estado São Paulo, Brazil (FAPESP 2008/02917-0 and 2009/06049-6), Conselho Nacional Pesquisa Desenvolvimento-Brasil CNPq (300447/2009-4), and A. Lapa: Fundação de Apoio À Pesquisa Estado São Paulo, Brazil (FAPESP 2010/ 13639-1).

\section{References}

[1] N. Fett and V. P. Werth, "Update on morphea: part I. Epidemiology, clinical presentation, and pathogenesis," Journal of the American Academy of Dermatology, vol. 64, no. 2, pp. 217-228, 2011.

[2] L. S. Peterson, A. M. Nelson, W. P. D. Su, T. Mason, W. M. O'Fallon, and S. E. Gabriel, "The epidemiology of morphea (localized scleroderma) in Olmsted County 1960-1993," Journal of Rheumatology, vol. 24, no. 1, pp. 73-80, 1997.

[3] J. J. Leitenberger, R. L. Cayce, R. W. Haley, B. Adams-Huet, P. R. Bergstresser, and H. T. Jacobe, "Distinct autoimmune syndromes in morphea: a review of 245 adult and pediatric cases," Archives of Dermatology, vol. 145, no. 5, pp. 545-550, 2009.

[4] S. Christen-Zaech, M. D. Hakim, F. S. Afsar, and A. S. Paller, "Pediatric morphea (localized scleroderma): review of 136 patients," Journal of the American Academy of Dermatology, vol. 59, no. 3, pp. 385-396, 2008.

[5] F. Zulian, B. H. Athreya, R. Laxer et al., "Juvenile localized scleroderma: clinical and epidemiological features in 750 children: an international study," Rheumatology, vol. 45, no. 5, pp. 614-620, 2006.
[6] M. Blaszczyk, C. K. Janniger, and S. Jablonska, "Childhood scleroderma and its peculiarities," Cutis, vol. 58, no. 2, pp. 141152, 1996.

[7] L. E. Eubanks, E. I. McBurney, W. Galen, and R. Reed, "Linear scleroderma in children," International Journal of Dermatology, vol. 35, no. 5, pp. 330-336, 1996.

[8] T. R. Katsumoto, M. L. Whitfield, and M. K. Connolly, "The pathogenesis of systemic sclerosis," Annual Review of Pathology, vol. 6, pp. 509-537, 2011.

[9] K. E. Holland, B. Steffes, J. J. Nocton, M. J. Schwabe, R. D. Jacobson, and B. A. Drolet, "Linear scleroderma en coup de sabre with associated neurologic abnormalities," Pediatrics, vol. 117, no. 1, pp. e132-e136, 2006.

[10] R. Vancheeswaran, C. M. Black, J. David et al., "Childhoodonset scleroderma: is it different from adult-onset disease?" Arthritis and Rheumatism, vol. 39, no. 6, pp. 1041-1049, 1996.

[11] C. T. Yamanaka and N. F. Gibbs, "Trauma-induced linear scleroderma," Cutis, vol. 63, no. 1, pp. 29-32, 1999.

[12] D. C. Salpietro, M. V. Merlino, S. Bruglia, F. Guarneri, and M. Vaccaro, "Linear scleroderma "en coup de sabre" associated with facial atrophy in a patient seropositive for Borrelia burgdorferi: a true case of molecular mimicry?" Pediatric Allergy and Immunology, vol. 15, no. 6, pp. 570-572, 2004.

[13] K. Eisendle, T. Grabner, and B. Zelger, "Morphoea: a manifestation of infection with Borrelia species?" British Journal of Dermatology, vol. 157, no. 6, pp. 1189-1198, 2007.

[14] C. Feghali-Bostwick, T. A. Medsger Jr., and T. M. Wright, "Analysis of systemic sclerosis in twins reveals low concordance for disease and high concordance for the presence of antinuclear antibodies," Arthritis and Rheumatism, vol. 48, no. 7, pp. 1956-1963, 2003.

[15] F. C. Arnett, M. Cho, S. Chatterjee, M. B. Aguilar, J. D. Reveille, and M. D. Mayes, "Familial occurrence frequencies and relative risks for systemic sclerosis (Scleroderma) in three United States cohorts," Arthritis and Rheumatism, vol. 44, no. 6, pp. 1359-1362, 2001.

[16] S. K. Agarwal and J. D. Reveille, "The genetics of scleroderma (systemic sclerosis)," Current Opinion in Rheumatology, vol. 22, no. 2, pp. 133-138, 2010.

[17] M. L. Whitfield, D. R. Finlay, J. I. Murray et al., "Systemic and cell type-specific gene expression patterns in scleroderma skin," Proceedings of the National Academy of Sciences of the United States of America, vol. 100, no. 21, pp. 12319-12324, 2003.

[18] H. Gardner, J. R. Shearstone, R. Bandaru et al., "Gene profiling of scleroderma skin reveals robust signatures of disease that are imperfectly reflected in the transcript profiles of explanted fibroblasts," Arthritis and Rheumatism, vol. 54, no. 6, pp. 19611973, 2006.

[19] G. Obermoser, B. E. Pfausler, D. M. Linder, and N. T. Sepp, "Scleroderma en coup de sabre with central nervous system and ophthalmologic involvement: treatment of ocular symptoms with interferon gamma," Journal of the American Academy of Dermatology, vol. 49, no. 3, pp. 543-546, 2003.

[20] M. H. Chung, J. Sum, M. J. Morrell, and D. S. Horoupian, "Intracerebral involvement in scleroderma en coup de sabre: report of a case with neuropathologic findings," Annals of Neurology, vol. 37, no. 5, pp. 679-681, 1995.

[21] R. M. Laxer and F. Zulian, "Localized scleroderma," Current Opinion in Rheumatology, vol. 18, no. 6, pp. 606-613, 2006.

[22] Y. Soma and M. Fujimoto, "Frontoparietal scleroderma (en coup de sabre) following Blaschko's lines," Journal of the American Academy of Dermatology, vol. 38, no. 2, pp. 366-368, 1998. 
[23] P. H. Itin and P. Schiller, "Double-lined frontoparietal scleroderma en coup de sabre," Dermatology, vol. 199, no. 2, pp. 185-186, 1999.

[24] D. L. Tuffanelli, "Localized scleroderma," Seminars in Cutaneous Medicine and Surgery, vol. 17, no. 1, pp. 27-33, 1998.

[25] K. L. Chiang, K. P. Chang, T. T. Wong, and T. R. Hsu, "Linear scleroderma "en coup de sabre": initial presentation as intractable partial seizures in a child," Pediatrics and Neonatology, vol. 50, no. 6, pp. 294-298, 2009.

[26] J. H. Jun, H. Y. Kim, H. J. Jung et al., "Parry-romberg syndrome with en coup de sabre," Annals of Dermatology, vol. 23, no. 3, pp. 342-347, 2011.

[27] I. Kister, M. Inglese, R. M. Laxer, and J. Herbert, "Neurologic manifestations of localized scleroderma: a case report and literature review," Neurology, vol. 71, no. 19, pp. 1538-1545, 2008.

[28] J. DeFelipe, T. Segura, J. I. Arellano et al., "Neuropathological findings in a patient with epilepsy and the parry-romberg syndrome," Epilepsia, vol. 42, no. 9, pp. 1198-1203, 2001.

[29] T. J. A. Lehman, "The Parry Romberg syndrome of progressive facial hemiatrophy and linear scleroderma en coup de sabre: mistaken diagnosis or overlapping conditions?" Journal of Rheumatology, vol. 19, no. 6, pp. 844-845, 1992.

[30] S. Appenzeller, M. A. Montenegro, S. San Juan Dertkigil et al., "Neuroimaging findings in scleroderma en coup de sabre," Neurology, vol. 62, no. 9, pp. 1585-1589, 2004.

[31] A. V. Marzano, S. Menni, A. Parodi et al., "Localized scleroderma in adults and children: clinical and laboratory investigations of 239 cases," European Journal of Dermatology, vol. 13, no. 2, pp. 171-176, 2003.

[32] I. Garcia-de la Torre, J. Castello-Sendra, T. Esgleyes-Ribot, G. Martinez-Bonilla, J. Guerrerosantos, and M. J. Fritzler, "Autoantibodies in Parry-Romberg syndrome: a serologic study of 14 patients," Journal of Rheumatology, vol. 22, no. 1, pp. 7377, 1995.

[33] S. Sato, M. Kodera, M. Hasegawa, M. Fujimoto, and K. Takehara, "Antinucleosome antibody is a major autoantibody in localized scleroderma," British Journal of Dermatology, vol. 151, no. 6, pp. 1182-1188, 2004.

[34] Y. Mimura, H. Ihn, M. Jinnin et al., "Anti-agalactosyl immunoglobulin G antibodies in localized scleroderma," International Journal of Dermatology, vol. 44, no. 10, pp. 817-820, 2005.

[35] H. E. Verhelst, H. Beele, R. Joos, B. Vanneuville, and R. N. Van Coster, "Hippocampal atrophy and developmental regression as first sign of linear scleroderma 'en coup de sabre," European Journal of Paediatric Neurology, vol. 12, no. 6, pp. 508-511, 2008.

[36] J. Stone, A. J. Franks, J. A. Guthrie, and M. H. Johnson, "Scleroderma "en coup de sabre": pathological evidence of intracerebral inflammation," Journal of Neurology Neurosurgery and Psychiatry, vol. 70, no. 3, pp. 382-385, 2001.

[37] S. Menni, A. V. Marzano, and E. Passoni, "Neurologic abnormalities in two patients with facial hemiatrophy and sclerosis coexisting with morphea," Pediatric Dermatology, vol. 14, no. 2, pp. 113-116, 1997.

[38] V. Falanga, T. A. Medsger Jr., M. Reichlin, and G. P. Rodnan, "Linear scleroderma: clinical spectrum, prognosis, and laboratory abnormalities," Annals of Internal Medicine, vol. 104, no. 6, pp. 849-857, 1986.

[39] D. E. Flores-Alvarado, J. A. Esquivel-Valerio, M. Garza-Elizondo, and L. R. Espinoza, "Linear scleroderma "en coup de sabre" and brain calcification: is there a pathogenic relationship?" Journal of Rheumatology, vol. 30, no. 1, pp. 193-195, 2003.

[40] J. David, J. Wilson, and P. Woo, "Scleroderma 'en coup de sabre," Annals of the Rheumatic Diseases, vol. 50, no. 4, pp. 260-262, 1991.

[41] K. Terstegge, B. Kunath, S. Felber, J. G. Speciali, H. Henkes, and N. Hosten, "MR of brain involvement in progressive facial hemiatrophy (Romberg disease): reconsideration of a syndrome," American Journal of Neuroradiology, vol. 15, no. 1, pp. 145-150, 1994.

[42] I. Unterberger, E. Trinka, K. Engelhardt et al., "Linear scleroderma "en coup de sabre" coexisting with plaque-morphea: neuroradiological manifestation and response to corticosteroids," Journal of Neurology Neurosurgery and Psychiatry, vol. 74, no. 5, pp. 661-664, 2003.

[43] M. Carreño, A. Donaire, M. I. Barceló et al., "Parry Romberg syndrome and linear scleroderma in coup de sabre mimicking Rasmussen encephalitis," Neurology, vol. 68, no. 16, pp. 13081310, 2007.

[44] J. Paprocka, E. Jamroz, D. Adamek, E. Marszal, and M. Mandera, "Difficulties in differentiation of Parry-Romberg syndrome, unilateral facial sclerodermia, and Rasmussen syndrome," Child's Nervous System, vol. 22, no. 4, pp. 409-415, 2006.

[45] J. R. Shah, C. Juhász, W. J. Kupsky et al., "Rasmussen encephalitis associated with Parry-Romberg syndrome," Neurology, vol. 61, no. 3, pp. 395-397, 2003.

[46] S. Grosso, A. Fioravanti, G. Biasi et al., "Linear scleroderma associated with progressive brain atrophy," Brain and Development, vol. 25, no. 1, pp. 57-61, 2003.

[47] P. Liu, Y. Uziel, S. Chuang, E. Silverman, B. Krafchik, and R. Laxer, "Localized scleroderma: imaging features," Pediatric Radiology, vol. 24, no. 3, pp. 207-209, 1994.

[48] E. T. Fain, M. Mannion, E. Pope, D. W. Young, R. M. Laxer, and R. Q. Cron, "Brain cavernomas associated with en coup de sabre linear scleroderma: two case reports," Pediatric Rheumatology, vol. 9, article 18, 2011.

[49] Y. Uziel, M. L. Miller, and R. M. Laxer, "Scleroderma in children," Pediatric Clinics of North America, vol. 42, no. 5, pp. 1171-1203, 1995.

[50] J. A. Fry, A. Alvarellos, C. W. Fink, M. E. Blaw, and E. S. Roach, "Intracranial findings in progressive facial hemiatrophy," Journal of Rheumatology, vol. 19, no. 6, pp. 956-958, 1992.

[51] G. Pupillo, F. Andermann, F. Dubeau et al., "Linear scleroderma and intractable epilepsy: neuropathologic evidence for a chronic inflammatory process," Annals of Neurology, vol. 39, no. 2, pp. 277-278, 1996.

[52] Y. Higashi, T. Kanekura, K. Fukumaru, and T. Kanzaki, "Scleroderma en coup de sabre with central nervous system involvement," Journal of Dermatology, vol. 27, no. 7, pp. 486$488,2000$.

[53] W. I. Schievink, J. F. Mellinger, and J. L. D. Atkinson, "Progressive intracranial aneurysmal disease in a child with progressive hemifacial atrophy (Parry-Romberg disease): case report," Neurosurgery, vol. 42, pp. 1195-1196, 1998.

[54] T. Bosman, J. V. B. Jnum, M. A. A. Van Walderveen, and P. A. Brouwer, "Giant intracranial aneurysm in a ten-year-old boy with Parry Romberg syndrome: a case report and literature review," Interventional Neuroradiology, vol. 15, no. 2, pp. 165$173,2009$.

[55] M. M. Tollefson and P. M. Witman, "En coup de sabre morphea and Parry-Romberg syndrome: a retrospective review of 
54 patients," Journal of the American Academy of Dermatology, vol. 56, no. 2, pp. 257-263, 2007.

[56] S. Sartori, G. Martini, M. Calderone, A. Patrizi, G. Gobbi, and F. Zulian, "Severe epilepsy preceding by four months the onset of scleroderma en coup de sabre," Clinical and Experimental Rheumatology, vol. 27, no. 3, supplement 54, pp. S64-S67, 2009. 


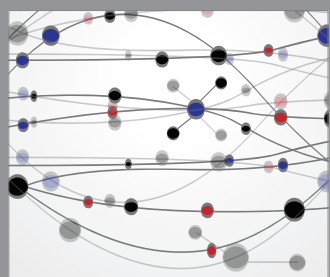

The Scientific World Journal
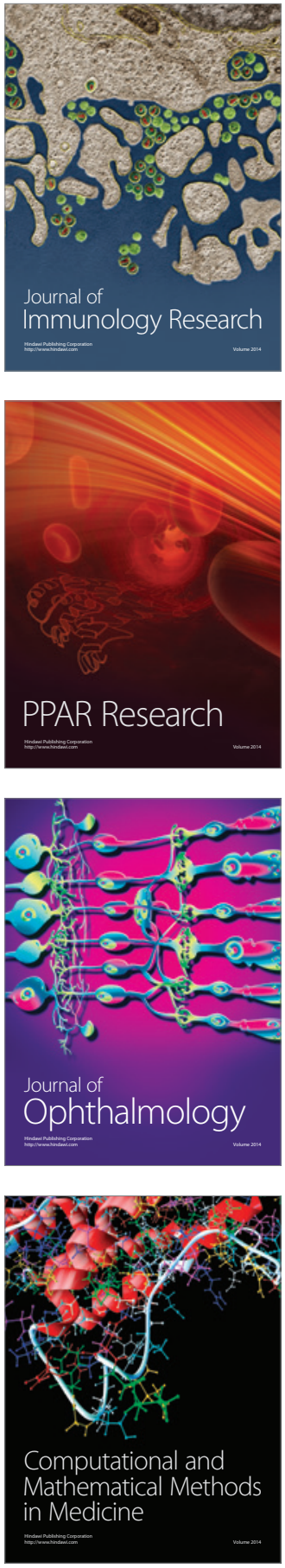

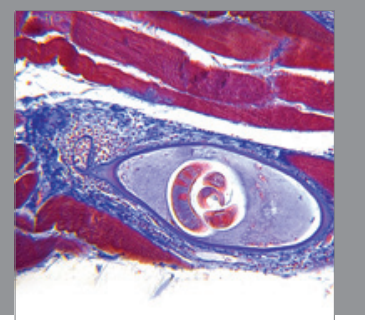

Gastroenterology

Research and Practice
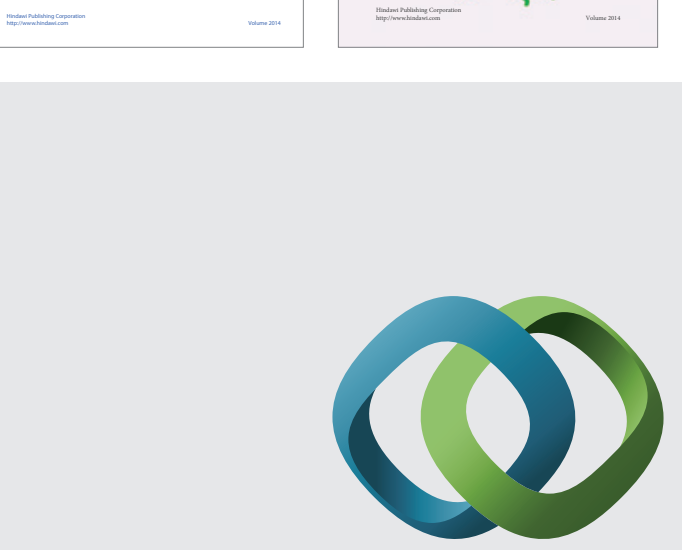

\section{Hindawi}

Submit your manuscripts at

http://www.hindawi.com
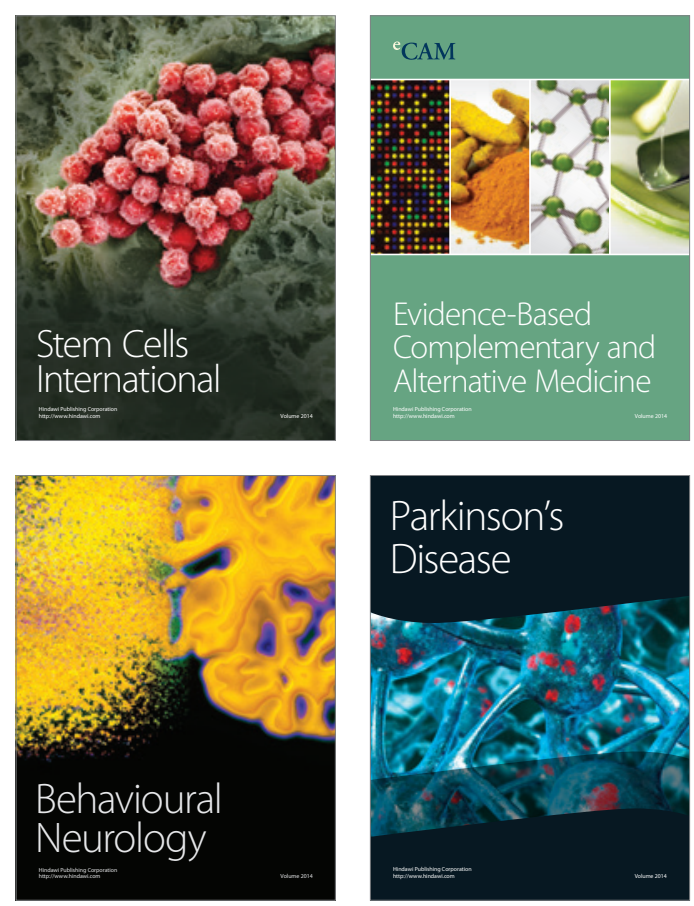

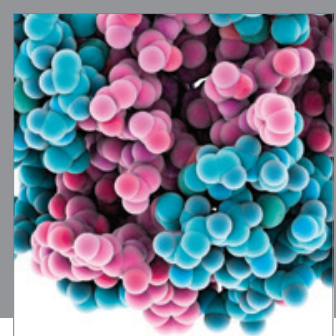

Journal of
Diabetes Research

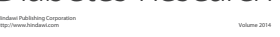

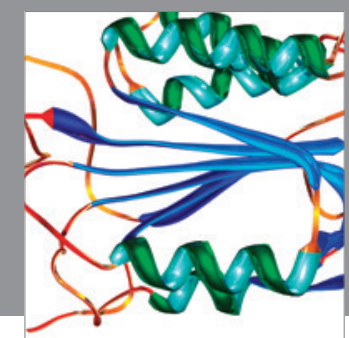

Disease Markers
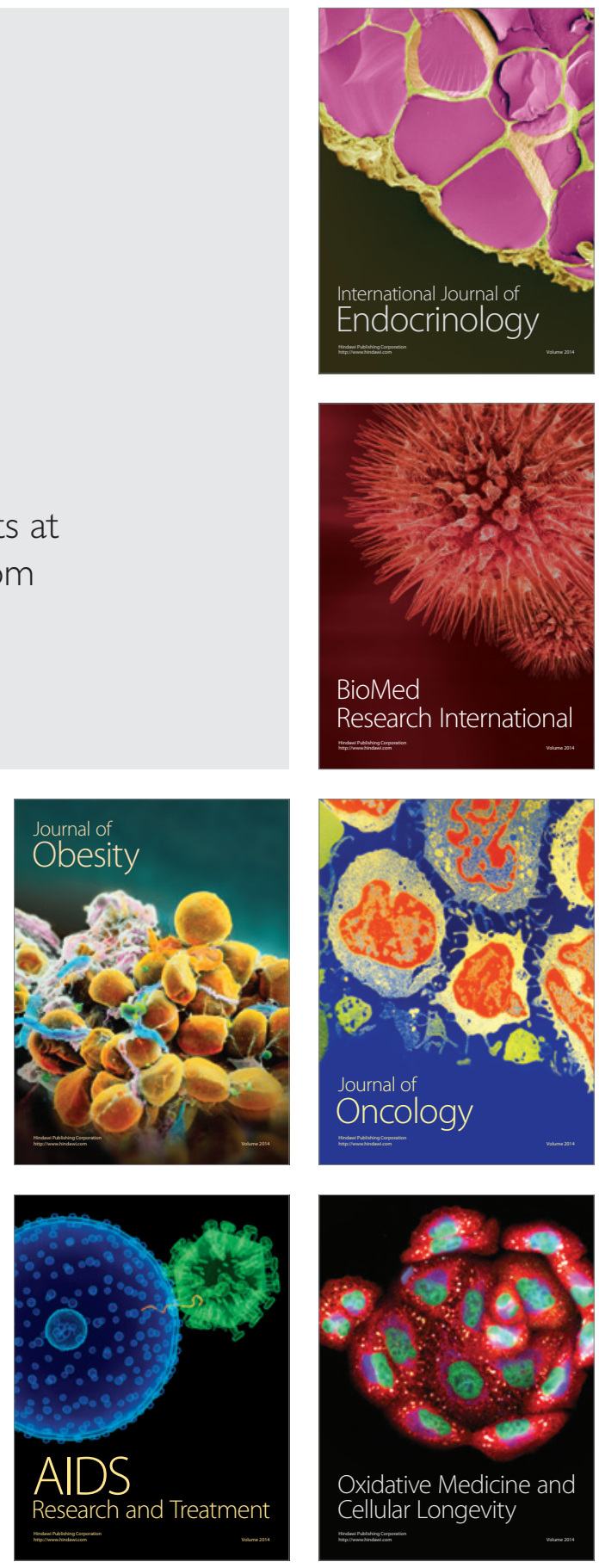